\title{
Miss Brasil Gay - Construindo imaginários sobre a cidade de Juiz de Fora - MG ${ }^{1}$
}

\author{
Miss Gay - Construyendo imágenes sobre la ciudad del Juiz de Fora- MG \\ Miss Brazil Gay - Building imagery about the city of Juiz de Fora - MG
}

\author{
Ms. Muryllo Rhafael Lorensoni ${ }^{2}$ \\ Dr. José Serafim Bertoloto 3 \\ Ms. Maria Regiane S. L. Barroso ${ }^{4}$ \\ Ms. Silvia Mara Davies 5
}

Da. Ana Graciela Mendes Fernandes da Fonseca Voltolini ${ }^{6}$

\begin{abstract}
Resumo
O presente texto observa por meio de uma pesquisa documental, um fenômeno da cultura urbana e da arte transformista, o concurso Miss Brasil Gay exerce o papel de atrativo para o desenvolvimento do turismo cultural e turismo de eventos além de trazer reconhecimento e olhares da mídia. Este estudo visa apresentar o evento, realizado na cidade mineira de Juiz de Fora há mais de 38 anos o que permeia imaginários como um local do protagonismo gay. O certame se destaca por ser a celebração de uma tradição urbana que movimenta o comércio local e população entorno de sua realização, o que instituiu o evento como o quarto Registro Imaterial do município, criando um imaginário sobre a cidade.
\end{abstract}

Palavras-Chave: Miss Brasil Gay; Imaginário; Cidade; Turismo Cultural.

\footnotetext{
${ }^{1}$ Artigo apresentado durante o I Congresso Internacional Online de Estudos sobre Culturas - \#Culturas, realizado de forma online, em outubro de 2019.

${ }^{2}$ Mestre e Doutorando em Estudos de Cultura Contemporânea; PPG em Estudos de Cultura Contemporânea (ECCO) - UFMT; Cuiabá, Mato Grosso, Brasil; mlorensoni@ hotmail.com”.

${ }^{3}$ Doutor em Comunicação e Semiótica pela Pontifícia Universidade Católica de São Paulo - PUC-SP. Docente do Programa de Pós-Graduação em Ensino da Universidade de Cuiabá - (UNIC). Docente Colaborador do Programa de Pós-Graduação em Estudos de Cultura Contemporânea na Universidade Federal de Mato Grosso (UFMT) E-mail: serafim.bertoloto@gmail.com. Lattes: http://lattes.cnpq.br/4937833975814371

${ }^{4}$ Mestre em Música e Doutoranda em Estudos de Cultura Contemporânea; PPG em Estudos de Cultura Contemporânea - (ECCO) - UFMT; Cuiabá, Mato Grosso, Brasil; regianemusique@gmail.com

${ }^{5}$ Mestre em Estudos de Cultura Contemporânea; PPG em Estudos de Cultura Contemporânea - (ECCO) -

UFMT; Cuiabá, Mato Grosso, Brasil; silvia.davies@srs.ifmt.edu.br

${ }^{6}$ Doutora em Comunicação Social - UMESP Professora do Programa de Pós-Graduação em Ensino da Universidade de Cuiabá - (UNIC); fonsecaanagraciela@gmail.com
} 


\begin{abstract}
Resumen
El presente texto observa por medio de la pesquisa documental, un fenómeno de la cultura urbana y el arte en transformación, el concurso Miss Brasil Gay desempeña el papel de atracción para el desarrollo del turismo cultural y el turismo de eventos, así como el reconocimiento y la atención de los medios. Este estudio pretende presentar el evento, realizado en la ciudad de Juiz de Fora por más de 38 años, que permea lo imaginario como un lugar de protagonismo gay. El evento se destaca como la celebración de una tradición urbana que mueve el comercio local y la población que rodea su logro, que instituyó el evento como el cuarto Registro Intangible del municipio, creando un imaginario sobre la ciudad.
\end{abstract}

Palabras claves: Miss Brasil Gay; Imaginario; Ciudad; Turismo cultural.

\begin{abstract}
The present text observes through a documentary research, a phenomenon of urban culture and transformist art, the Miss Brasil Gay contest plays the attractive role for the development of cultural tourism and event tourism, besides bringing recognition and media glances. This study aims to present the event, held in the city of Juiz de Fora for over 38 years, which permeates the imagination as a place of gay protagonism. The event stands out for being the celebration of an urban tradition that moves the local commerce and population around its holding, which established the event as the fourth Intangible Registry of the municipality, creating an imaginary about the city.
\end{abstract}

Keywords: Miss Brasil Gay; Imaginary; City; Cultural tourism.

\title{
1. Introdução
}

A partir de leituras e vivências sobre o Miss Brasil Gay, percebemos o quanto esse objeto é campo fértil para discutir as identidades das minorias sociais no Brasil, a arte, os eventos culturais e a noção de cidade por um caminho transverso: a realização de um concurso de beleza que elege o mais belo transformista do Brasil e se torna referência nacional, permeando o imaginário da uma cidade.

A cidade foi, desde o princípio, espaço de uma nova sensibilidade. Portar um ethos urbano, habitar a cidade implicou maneiras de representa-la, modificadas ao longo do tempo.

...fosse pela palavra, escrita ou falada, fosse pela música, em melodias e canções que a celebravam, fosse pelas imagens, desenhadas, pintadas ou projetadas, que a representavam, no todo ou em parte, fosse ainda pelas práticas cotidianas, pelos rituais e pelos códigos de civilidade presentes naqueles que a habitavam. Às cidades reais, concretas, visuais, tácteis, consumidas e usadas no dia-a-dia, corresponderam outras tantas cidades imaginárias, a mostrar que o urbano é bem a obra máxima do homem, obra esta que ele não cessa de reconstruir, pelo pensamento e pela ação, criando outras tantas cidades, no pensamento e na ação, ao longo dos séculos.(PESAVENTO 2007, p.6) 
Para Canclini (2008), até meados do século XX o pensamento urbano definia a cidade de forma raza, ligada ao espaço físico: cidade é o oposto do campo, ou um tipo de agrupamento extenso e denso de indivíduos socialmente heterogêneos. Nas últimas décadas, tenta-se caracterizar o urbano levando em conta também os processos culturais e os imaginários dos que o habitam.

As cidades além de territórios, construções e interações materiais entre aqueles que a habitam, também se formam a partir dos campos imaginativo, das informações e dos modos de experimentar as interações sociais. Ao compreender a cidade desta forma, às explicações demográficas e socioeconômicas, assim como às representações culturais nas quais se manifestam a heterogeneidade e a complexidade do social descrevem a cidade de forma mais densa.

A representação, elemento fundamental do imaginário social, que o transporta do universo simbólico para o mundo social, é analisada por Chartier (2002), como um conjunto de classificações, divisões e hierarquizações que definem a compreensão do mundo social a partir de orientações dos grupos ou classes sociais, ou suas frações, variáveis de acordo com a posição de cada um em determinados espaços da sociedade.

Nenhuma análise abarca a totalidade dos processos urbanos e dos imaginários que ela engendra. Os próprios espaços urbanos, proporcionam experiências de desconhecimento, assim, a comunicação passa a exercer poder sobre as diversas esferas, muitas vezes definindo ou redefinindo o contorno das diversas identidades, a construção do pensamento na contemporaneidade permeia os processos de comunicação: ao mesmo tempo que apresentam fatos, promovem ações que valorizam a cultura, criam imaginários locais. As identidades não são mais ser percebidas apenas pelas fronteiras geográficas, entretanto, no que tange ao concurso, o local 'Juiz de Fora-MG' é emblemático, no sentido de que é este o lugar, simbolicamente, que atua quase como um altar para eleger a Miss Brasil Gay, um evento que se consolida como tradição no município, que movimenta a economia local como nenhum outro e que ganhou o carisma da população.

Bourdieu (2011) propõe perceber ao mesmo tempo a realidade da representação como elemento concreto e a representação da realidade, como disputas materiais e simbólicas moldam a percepção da realidade. Como espaço dinâmico o campo do concurso de Miss Brasil Gay, integra disputas sociais simbólicas, por estratégias discursivas e pelas 
representações sociais, produtos históricos formulados a partir das disputas por hierarquização e dominação.

Mas para se analisar a relação entre campo e imaginário social, torna-se fundamental verificar o que se compreende como imaginário (em sentido amplo) e imaginário social.

\footnotetext{
O conjunto das imagens não gratuitas e das relações de imagens que constituem o capital inconsciente e pensado do ser humano. Este capital é formado pelo domínio do arquetipal - ou das invariâncias e universais do comportamento do gênero humano - e pelo domínio do idiográfico, ou das variações e modulações do comportamento do homem localizado em contextos culturais específicos e no interior de unidades grupais. (COELHO 1997, p.78)
}

Como metodologia, foi utilizada a revisão bibliográfica, pautada em textos e artigos que versam sobre os temas: Miss Brasil Gay Juiz de Fora, Cidades, Turismo e Patrimônio. A fim de compreender e levantar informações sobre o evento, utilizamos Rodrigues (2008) e Pereira \& Anjos (2011), para falar de cidades recorremos a Canclini (2008), sobre o imaginário, Bourdieu (2011) e Chartier (2002).

\section{Miss Brasil Gay Juiz de Fora}

A preservação do patrimônio enquanto atrativo turístico, como o patrimônio cultural, sobretudo daqueles tombados ou registrados, as manifestações culturais, como a arte, as tradições e as festividades, seriam recursos concernentes à cultura, no intuito de servir como matriz da atividade turística, sobretudo pelo interesse que esses bens despertam nos potenciais visitantes, além do significado para dada população, capazes, em alguns casos, de atrair milhares de turistas, como é o caso do Miss Brasil Gay, realizado anualmente em Juiz de Fora, Minas Gerais.

Para Pesavento (2007), os eventos e acontecimentos da cidade corroboram na construção do seu imaginário construído pelo pensamento e que identifica, percebe e qualifica a forma, o volume, as práticas e os atores desse espaço urbano vivido e visível, permitindo que enxerguemos, vivamos e apreciemos desta ou daquela forma a realidade tangível. A cidade é responsável pela atribuição de sentidos e significados ao espaço e ao tempo que se realizam na e por causa da cidade.

Os concursos de miss, sejam tradicionais normativos ou em versões subalternas como o Miss Gay, geraram ao longo da história uma série de discussões, principalmente em relação 
ao gênero, tais concursos acompanharam transformações sociais e perduram até hoje, é inegável que no Brasil o auge dos concursos de beleza foram as décadas 70 e 80, fato que neste período os certames tinham mais espaço na mídia, principalmente televisiva. Momento de relevância também para a cena gay que começa a ganhar espaços perante o urbano.

A conquista dos espaços gays na sociedade passou pelo mercado, sendo o setor de viagens e turismo para o público gay precedido pela expansão de entretenimento segmentado. Na década de 1980, começaram a surgir, nos grandes centros como São Paulo e Rio de Janeiro, bares, boates e espaços destinados ao público gay (TRIGO, 2009, p. 149).

Idealizador do concurso, o cabeleireiro mineiro Francisco Motta, participava dos concursos de Miss Brasil no maracanãzinho (Rio de Janeiro), resolveu em 1979, no intuito de angariar fundos para uma escola de samba de Juiz de Fora, realizar o que viria a ser o primeiro concurso de transformistas do Brasil. As primeiras candidatas foram os apaixonados por concursos de beleza e misses, pelas cantoras, pelas estrelas do cinema um grupo de amigos praticava o transformismo em Juiz de Fora dos anos 70.

Quase quatro décadas depois, o Miss Brasil Gay é considerado hoje o mais importante concurso de beleza transformista do país, uma competição que envolve todos os estados brasileiros e o distrito federal. A mecânica do concurso é a mesma utilizada em concursos normativos. As candidatas são eleitas em concursos realizados em diferentes cidades que acontecem sob a responsabilidade dos "coordenadores de estado", o concurso trabalha a ideia de patriotismo e representatividade de origens, ao passo que cada candidata atua como representante de sua cidade/estado de origem. A disputa se divide em duas etapas: traje típico e traje de gala. Há ainda a eleição da Miss Simpatia. A avaliação se dá por um corpo de jurados, sob a presidência do coordenador geral do evento.

O concurso, em todas as suas edições, sempre aconteceu na cidade, geralmente em um grande ginásio esportivo, exceto por algumas tentativas frustradas de realizar algumas edições no teatro da cidade. Fato curioso é que com o passar dos anos e com o surgimento de outros concursos do mesmo segmento, foi necessário utilizar um artifício para diferenciar este concurso dos demais, assim, a consolidação do concurso em Juiz de Fora se tornou sinônimo de tradição e credibilidade sendo nomeada a miss eleita como Miss Brasil Gay versão Juiz de Fora, fato que contribui para a criação do imaginário da cidade.

Para Canclini (2008), as cidades vão se transformando mediante o conhecimento e a cultura, aos poucos convertemos as cidades em espetáculo cultural e em um momento de 
industrialização da cultura corremos o risco de ocultarmos necessidades sociais no âmbito urbano ao reduzirmos a cidade a espetáculo, assim, estaríamos associando este espetáculo ao predomínio do marketing e à captação de investimentos sobre os bens materiais e simbólicos.

\begin{abstract}
Estamos transformando as cidades mediante o conhecimento e a cultura ou convertemos as cidades em espetáculo cultural sem modificar as desordens estruturais? A espetacularização do social existe desde há séculos (missas, desfiles, e outros ritos massivos), mas sua hipertrofia numa época de industrialização da cultura aumenta o risco de nos desviarmos da satisfação de necessidades sociais: no âmbito urbano, a redução da cidade a espetáculo se associa ao predomínio do marketing e à captação de investimentos sobre o sentido social dos bens materiais e simbólicos. (CANCLINI 2008 p.19)
\end{abstract}

Uma das maiores festas nacionais direcionadas para o público Gay e celebração tradicional da cultura, fatos que possibilitaram o Registro da festividade como o Quarto Bem Imaterial do Município, sendo os demais: o apito do meio dia, Banda Daki e o Batuque Afrobrasileiro de Nelson Silva, processo realizado pelo Conselho Municipal de Preservação do Patrimônio Cultural - COMPPAC e ratificado pelo prefeito Alberto Bejani. A partir do exposto é possível levantarmos algumas questões já debatidas por outros pesquisadores Graziela Dias Pereira e Edwaldo Sérgio dos Anjos Junior, em seu texto Vínculos entre Turismo, Eventos e o Patrimônio Imaterial em Juiz de Fora, Minas Gerais: uma reflexão sobre processo de registro do "Miss Brasil Gay" publicado em 2011, onde os autores debatem os benefícios simbólicos e econômicos trazidos pelo registro, se eles existiram efetivamente ou não.

Mas a cidade, na sua compreensão, é também sociabilidade: ela comporta atores, relações sociais, personagens, grupos, classes, práticas de interação e de oposição, ritos e festas, comportamentos e hábitos. Marcas, todas, que registram uma ação social de domínio e transformação de um espaço natural no tempo. (PESAVENTO 2007, p.9)

Aqueles que participam do evento, seja in loco, no caso dos turistas ou acompanhando a repercussão midiática, desconhecem os problemas estruturais da cidade, o imaginário se constrói a partir daquilo que é apresentado e evidenciado pelo concurso, a espetacularização social, evidencia aquilo de bom e de atrativo que aquele espaço tem a oferecer. 
As mídias apresentam perspectivas por vezes totalizantes, disparam olhares que apresentam fatos que não podem representar aquele lugar de forma abrangente. A cidade é múltipla, diversa, complexa, são vários os dizeres e as trocas, reduzir a cidade ao evento seria compreendê-la de forma superficial.

A fragmentação das experiências registrada nos estudos sobre diversidade cultural urbana torna evidente que não há saberes totalizadores. Nem o prefeito da cidade, nem o melhor especialista em planejamento urbano têm uma visão em profundidade do conjunto; mas chama a atenção, de vez em quando, que no desenvolvimento comunicacional apareçam simulacros de totalização.(CANCLINI 2008 p. 21)

Os meios de comunicação atuam sobre os imaginários e se constituem em reconfigurador de uma totalidade que ninguém percebe. Uma variante possível dessa rearticulação comunicacional é oferecida pelos smartphones conectados a internet que permitem interagir à distância, embora não detenham o mesmo aparato dos meios profissionais de comunicação colaboram com o imaginário abarcador multilocal ao exibirem ações que acontecem na cidade.

Ao estarmos dependentes do que nos dizem no rádio ou na televisão sobre o que aconteceu na cidade, manifestamos, por um lado, um desejo de conhecimento e, por outro, uma carência que se torna difícil de suportar. Esses dois impulsos estão na base dos imaginários. O imaginário não é apenas a representação simbólica do que ocorre, mas também um lugar de elaboração de insatisfações, desejos e busca de comunicação com os outros. Os desequilíbrios e incertezas engendrados pela urbanização que desurbaniza por sua expansão irracional e especulativa parecem compensados pela eficácia tecnológica das redes comunicacionais. (CANCLINI 2008 p. 22)

\section{Conclusões}

Não nos restam dúvidas da importância do concurso Miss Brasil Gay para a cidade de Juiz de Fora - MG, seja na esfera política, turística, econômica e social, o concurso se apresenta como referência nacional no segmento. Dada relevância fez como que o evento fosse instituído como o quarto Bem Imaterial Registrado pelo município sede, para isso também foram levados em considerações os fatos do concurso ser um dos mais grandiosos eventos gay do país e a tradição que ele representa em seus 39 anos de existência. Mesmo 
sendo um evento que envolve todo o país, uma vez que acolhe candidatas e caravanas de todos os estados brasileiros, não é despendida muita importância para o registro deste bem nesta esfera. $\mathrm{O}$ evento é um bem significativo para a população que acolheu o concurso como peça de sua cultura local, ao mesmo tempo que cria um imaginário em relação a cidade como uma cidade gay friendly, que respeita a diversidade e é contra preconceitos.

O fato do concurso ser reconhecido como Bem Imaterial Cultural de Juiz de Fora, não trouxe modificações diretas na dinâmica do evento/concurso, entretanto mudou a forma de recepção do concurso perante o seu público e principalmente perante a população juizforense, segundo Pereira (2011), o concurso ganhou o carisma dos habitantes de Juiz de Fora e após o registro o evento se consagrou como cultura local.

Concluímos que conseguir uma maior visibilidade para o evento foi importante para o movimento LGBT, pois contribuiu para o reconhecimento das causas, a história do concurso está intimamente relacionada a história da cidade.

\section{Referências}

AZE ABRAMO, M. C. Turismo GLBT: a importância do Miss Brasil Gay e sua contribuição para a cidade de Juiz de Fora, 2008. Trabalho de Conclusão de Curso (Graduação em Turismo) - Instituto de Ciências Humanas, Universidade Federal de Juiz de Fora, Juiz de Fora, 2008.

BOURDIEU, Pierre. A distinção: crítica social do julgamento. 2 Ed. Porto Alegre: Zook, 2011.

CANCLINI, N.G. in A cultura pela cidade / Teixeira Coelho (org.). - São Paulo : Iluminuras : Itaú Cultural, 2008.il.

CHARTIER. R. O mundo como representação. In: À beira da falésia: a história entre incertezas e inquietude. Trad. Patrícia Chittoni Ramos. Porto Alegre: Ed. Universidade/UFRGS, 2002, p. 61-80.

COELHO, T. Dicionário crítico de política cultural: cultura e imaginário. São Paulo: Iluminuras, 1997.

MOESCH, M. Por uma epistemologia do Turismo. In: MOESCH, M. A produção do saber Turístico. 2. ed. São Paulo: Contexto, 2002.

PEREIRA, G.D; ANJOS, E.S. - Vínculos entre Turismo, Eventos e o Patrimônio Imaterial em Juiz de Fora, Minas Gerais: uma reflexão sobre processo de registro do "Miss Brasil Gay”. Juiz de Fora - ABET, 2011. 
PERALTA, E. O mar por tradição: o patrimônio e a construção das imagens do turismo. Horizonte antropológico. Porto Alegre, v. 9, n. 20. 2003.

PESAVENTO, S. Cidades visíveis, cidades sensíveis, cidades imaginárias. Rev. Bras. Hist. vol.27 no.53 São Paulo, 2007.

RODRIGUES, M. C. Miss Brasil Gay, polêmica na passarela -Eventos como instrumento de comunicação alternativa. Juiz de Fora - UFJF, 2008. 